\title{
ATIVIDADE TURÍSTICA NA CIDADE DO RECIFE: LEVANTAMENTO E DIAGNÓSTICO DE SÍTIOS ARQUEOLÓGICOS
}

\author{
Vanessa Rodrigues da Silva ${ }^{1}$ \\ Cláudia Alves de Oliveira ${ }^{2}$
}

\begin{abstract}
RESUMO
Nesta pesquisa, foi realizado o levantamento e diagnóstico dos sítios arqueológicos localizados no bairro do Recife Antigo em Pernambuco, que estão sendo utilizados como produtos turísticos: Sinagoga KahalZur Israel, Igreja da Madre de Deus, Forte do Brum, Museu a Céu Aberto, Forte das Cinco Pontas e Bolsa de Valores de Pernambuco e Paraíba (hoje, Caixa Cultural). Nesta perspectiva, foi analisada a infra-estrutura turística e elaborada uma proposta de roteiro turístico envolvendo os sítios arqueológicos encontrados. O Turismo Arqueológico pode ser mais uma ferramenta para preservar e proteger esse patrimônio e permite introduzir a comunidade local no contexto turístico de forma que consiga participar do desenvolvimento da própria localidade. Entretanto, se faz necessário que os sítios encontrados e utilizados nesse processo econômico sejam bem estruturados, não sejam descaracterizados e continuem a transmitir conhecimento às demais gerações.
\end{abstract}

PALAVRAS-CHAVE: Turismo Arqueológico; Sítios Arqueológicos; Produtos turísticos; Preservação; Diagnóstico.

\begin{abstract}
In this research it performed a study and diagnosis of archaeological sites, located in the neighborhood of Recife Antigo in Pernambuco, being used as tourist products: SinagogaKahalZur Israel, Igreja da Madre de Deus, Forte do Brum, Museu a CéuAberto, Forte das CincoPontas, and Bolsa de Valores de Pernambuco e Paraíba (currently, Caixa Cultural). In this perspective it analyzed the tourist infrastructure and prepared a proposal for tourist route involving the archaeological sites found. The Archaeological Tourism can be a tool to preserve and protect this heritage and allows you to enter the local community in the tourism context so that can participate in the development of their own locality. However, it is necessary that the sites found and used in this economic process, are well structured, are not adulterated and continue to impart knowledge to other generations.
\end{abstract}

Keywords: Archaeological tourism; Archaeological Sites; Tourism products; preservation; Diagnosis.

\footnotetext{
${ }^{1}$ Bacharel em Turismo (DHT - UFPE); Mestranda em Arqueologia (PPARQ-UFPE). Contato: vanessrodrigues@hotmail.com

${ }^{2}$ Docente/pesquisador do Depto de Arqueologia - CFCH - UFPE. E-mail: olivas@hotlink.com.br Endereço: Rua Prof. Moraes Rego, 1235 - Cidade Universitária, Recife-PE. CEP: 50670-901. Fone: (081) 99704-4339
}

\begin{tabular}{|l|l|l|l|l|l|l|} 
(C) Rev. Arqueologia Pública & Campinas, SP & v.9 & n.2 & p.3-18 & DEZ-2015 & ISSN 2237-8294
\end{tabular}




\section{RESUMEN}

En esta investigación se realizó un estudio y diagnóstico de los sitios arqueológicos que se encuentra en el barrio del Recife Antigo, en Pernambuco, que se utiliza como productos turísticos: Sinagoga KahalZur Israel, Igreja da Madre de Deus, Forte do Brum, Museu a Céu Aberto, Forte das Cinco Pontasand Pernambuco e Bolsa de Valores de Pernambuco e Paraíba (actualmente, Caixa Cultural). En esta perspectiva se analiza la infraestructura turística y preparamos una propuesta de ruta turística que involucra los yacimientos arqueológicos encontrados. El turismo arqueológico puede ser una herramienta para preservar y proteger este patrimonio y le permite entrar en la comunidad local en el contexto del turismo para que puedan participar en el desarrollo de su propia localidad. Sin embargo, es necesario que los sitios encontrados y utilizados en este proceso económico están bien estructurados, no están adulterados y continúan para impartir conocimientos a otras generaciones.

Palabras clave: Turismo Arqueológico; Sitios Arqueológicos; Los productos turísticos; Preservación; Diagnóstico.

\section{INTRODUÇÃO}

Pode-se dizer que a evolução do turismo iniciou-se no início do século XVII, quando as famílias que detinham posses começaram a mandar seus filhos para estudar arte, línguas e cultura de outras localidades, por exemplo, Viena e Roma, já conhecidas devido às escolas de ensino superior. A locomoção era precária, por isso dificultava o percurso, retardando, assim, as viagens. Após o aprimoramento dos transportes, no fim do século XVIII, a atividade turística, de forma sistemática, começou a seguir rumos diferentes a partir do século XX.

O turismo possui algumas definições que foram se estabelecendo no decorrer dos anos para moldar as referências conceituais. Uma das mais aceitáveis é a da Organização Mundial do Turismo (OMT, 2003), que define como "o deslocamento e as atividade realizadas pelas pessoas durante suas viagens e estadas, bem como, as relações que surgem entre eles, em lugares distintos de seu ambiente natural, por período de tempo [...] principalmente com fins de lazer, negócio e outros".

No inicio da atividade, não se tinha a ideia de turismo estruturado como se tem hoje e que foi definido por seus diversos segmentos através do Plano Nacional de Turismo (PNT) do Ministério do Turismo MTur. Essa segmentação seria a forma de organizar o turismo, como uma estratégia para a estruturação de produtos, consolidação de roteiros e destinos, a partir dos elementos de identidade de cada região (MTUR, 2006: 11). É uma forma, portanto, de reunir elementos comuns que atraiam turistas que tenham o interesse em conhecer tais elementos. Pode-se destacar, entre outros, o turismo de sol e mar - voltado para o público que tenha interesse em conhecer diversas praias do litoral brasileiro; o turismo de eventos - voltado para os turistas que buscam novidades nos diversos tipos de eventos; o turismo de aventura - para aqueles que se emocionam nos esportes radicais - e o turismo cultural. 
A atividade turística possui como uma das bases primordiais, sem dúvidas, o patrimônio cultural. Neste segmento do turismo, as pessoas se deslocam atraídas pelo patrimônio natural ou cultural, integrando marco geográfico-ecológico-cultural de lugar (BENI, 2008, p.92). Esse conceito engloba, portanto, os patrimônios materiais, imateriais e naturais que constituem a cultura de um povo ou de uma região.

O objeto de estudo dessa pesquisa são os Sítios Arqueológicos utilizados no âmbito do turismo no Recife Antigo no estado de Pernambuco. Enquadra-se, portanto, no segmento do turismo cultural, no campo do Arqueoturismo e, naturalmente, com o patrimônio material.

Através do turismo cultural, as pessoas aprendem sobre as formas de vida e pensamento umas das outras, sendo, conforme Goeldner (2002: 33), um importante meio para promover relações culturais e cooperação intercultural. Compreendem, dessa forma, as atividades turísticas relacionadas à vivência do conjunto de elementos significativos do patrimônio histórico e cultural, dos eventos culturais, valorizando e promovendo os bens materiais e imateriais da cultura (MTUR, 2006: 12).

A cultura pode ser entendida, na concepção de Beni (2008: 92), como o "conjunto de crenças, valores e técnicas para lidar com o meio ambiente compartilhado entre os contemporâneos e transmitido de geração a geração". Nesta perspectiva, o autor defende a atividade turística como propulsora da cultura dos povos que habitam os destinos turísticos, contribuindo para a preservação de valores culturais, os quais apresentam também um valor específico para o turista.

O turismo cultural tem alcançado notoriedade no cenário pernambucano, pois possui um acervo de grande significado histórico-cultural. Encontra-se consolidado nos países da Europa e vem se fortalecendo nas Américas e na Ásia, por ser uma atividade que proporciona aos turistas o conhecimento da cultura visitada - tradição, gastronomia, vestimenta, músicas, lendas, etc. Assim sendo, o Turismo Arqueológico está inserido nesse grande e complexo segmento do Turismo Cultural. Através dos sítios arqueológicos, tanto os turistas quanto a população local pode perceber a importância do passado histórico da cidade. Porém essa atividade não deve ser realizada aleatoriamente e sim após estudos, para que dessa forma esses sítios não sejam, ao longo dos anos, destruídos devido à má utilização.

O Ministério do Turismo expõe quais os patrimônios considerados interessantes para serem utilizados como produtos turísticos. Isto inclui os bens culturais de valor histórico, artístico, científico e simbólico e são:

Passíveis de se tornarem atrações turísticas: arquivos, edificações, conjuntos urbanísticos, sítios arqueológicos, ruínas, museus e outros espaços destinados à apresentação ou contemplação de bens materiais e 
imateriais, manifestações como música, gastronomia, artes visuais e cênicas, festas e celebrações. (MTUR, 2006: 20).

Os Sítios Arqueológicos estão despertando o interesse, não somente dos pesquisadores, mas, também, dos turistas e, consequentemente, do trade turístico - os empresários. $\mathrm{Na}$ Carta de Lausanne, são considerados como bens patrimoniais e, assim definidos como:

A porção do patrimônio material para o qual os métodos de arqueologia fornecem conhecimentos primários. Engloba todos os vestígios da existência humana e interessa todos os lugares onde há indícios de atividades humanas, não importando quais sejam elas, estruturais e vestígios abandonados, de todo tipo, na superfície, no sub-solo ou sob as águas, assim como o material a eles associados (CARTA DE LAUSANNE, 1990: 02).

Os Sítios Arqueológicos são, portanto, os locais onde se podem encontrar vestígios da cultural material, ou seja, resquícios de materiais orgânicos e inorgânicos - cerâmica, faiança, telhas, tijolos, estruturas arquitetônicas, carvão de uma antiga fogueira - de povos antigos. A partir desses vestígios, são recuperadas diversas informações sobre aspectos da tecnologia, o modo de produção, as relações sociais e sobre o mundo simbólico das populações do passado. Isto desperta interesse de pessoas que têm sede de conhecer a cultura de outros povos e como os antepassados destes viviam.

Por se considerar que o conhecimento deve ser transmitido tanto para a comunidade - pois esta, muitas vezes, desconhece a importância da história local - quanto para os turistas - que desejam conhecer modos distintos dos seus - é que os Sítios Arqueológicos estão sendo dispostos à visitação. Tornando-se, assim, produtos turísticos e objeto do segmento Turismo Arqueológico que encontra-se definido como o deslocamento de pessoas a sítios arqueológicos, escavações e cavernas com inscrições e pinturas rupestre (BENI, 2008: 482). Posteriormente, Manzato (2007: 01) amplia essa definição, especificando os tipos de sítios em "pré-históricos e/ou históricos, passíveis de visitação terrestre ou aquática".

Essa atividade já está bastante consolidada em muitos países da Europa e Ásia. Segue em desenvolvimento nos países das Américas como exemplo, no Brasil, onde começa, apesar de lento, a ser desenvolvida (MANZATO, 2007: 01).

Verifica-se no Brasil um grande potencial para este segmento, ocorrendo já uma demanda. No Nordeste, em algumas áreas onde existem pesquisas arqueológicas, como o Parque Nacional da Serra da Capivara, no Piauí, e o Bairro do Recife, em Pernambuco, os sítios arqueológicos estão sendo utilizados como atrativos arqueoturísticos.

\begin{tabular}{|l|l|l|l|l|l|l|}
\hline (C) Rev. Arqueologia Pública & Campinas, SP & v.9 & n.2 & p.3-18 & DEZ-2015 & ISSN 2237-8294 \\
\hline
\end{tabular}


Com a finalidade de realizar o diagnóstico do turismo arqueológico na cidade do Recife, em Pernambuco, foi realizado o levantamento e cadastramento dos sítios arqueológicos que estão sendo utilizados ou que poderiam ser utilizados como produtos turísticos nesta cidade. Outro objetivo desta pesquisa foi o de analisar o estado de conservação e preservação dos sítios arqueológicos. Procurou-se identificar o potencial arqueológico de forma que se possa ampliar o produto turístico cultural no Recife. Considera-se que a utilização dos sítios arqueológicos é um importante meio de propagar a cultura, tanto para os autóctones, como para os turistas. A gestão do Patrimônio bem planejada permite evitar a sua degradação e o turismo pode auxiliar na sua preservação.

O bairro do Recife, comumente conhecido por Recife Antigo, é registrado como um sítio arqueológico, tombado pelo o Instituto do Patrimônio Histórico e Artístico Nacional (IPHAN). Nesta área foi possível destacar, como pontos de atividades turísticas, as unidades já escavadas, a Sinagoga KahalZur Israel, o Forte do Brum, o Museu ao Céu Aberto, a Igreja da Madre de Deus e a Bolsa de Valores de Pernambuco e Paraíba. Os estudos são indispensáveis para que os mesmos possam ser destinados à visitação, sem que haja a descaracterização parcial ou total, de forma a serem preservados para as próximas gerações. O objetivo geral desta pesquisa foi, portanto, realizar o diagnóstico desses sítios, analisar o estado de conservação e preservação, propor a utilização de novos sítios arqueológicos e elaborar proposta de roteiros turísticos, com a finalidade de ampliar as opções de atrativos turísticos na cidade do Recife.

\section{METODOLOGIA DO TRABALHO}

É indispensável em uma pesquisa encontrar métodos que minimizem ocorrências de erros na obtenção do resultado final. Esta pesquisa teve abordagem metodológica de caráter: exploratório, descritivo e qualitativo. Este último aborda a realidade que não pode ser quantificada, centrando-se na compreensão e explicação da dinâmica das relações sociais (FONSECA, 2002: 31).

O aspecto exploratório considera que existe uma relação entre o mundo e o sujeito que não pode ser traduzida em números. Busca levantar informações sobre um determinado objeto, delimitando, assim, um campo de trabalho, mapeando condições de manifestação desse objeto (ALMEIDA, 2006: 02; SEVERINO, 2012: 123).

Já na abordagem descritiva, os fatos são observados, registrados, analisados, classificados e interpretados sem interferência do pesquisador. No turismo, é a mais utilizada e recomendada quando o objetivo da pesquisa é a descrição sistemática, objetiva e precisa das características de uma determinada população ou área de interesse (RODRIGUES, 2007: 04; SCHLÜTER, 2003: 77). 
A pesquisa bibliográfica foi realizada sobre diversos temas relacionados ao turismo arqueológico no âmbito atual, o patrimônio material, arqueologia, sítios arqueológicos e cultura material. Para a observação das unidades arqueológicas, neste caso os sítios, foi elaborado um protocolo baseado nos critérios utilizados por Manzato (2007: 02), onde esta ressalta que para a análise da infraestrutura turística deve-se verificar as condições que possibilitam a visitação turística nos sítios, tais como, disponibilidade de sanitários, placas indicativas e informativas, monitoria, áreas específicas para alimentação e descanso, material turístico impresso, entre outros. Dessa forma, foram considerados os seguintes aspectos: infraestrutura (por exemplo, vidros e grades de proteção), acesso ao local, painéis explicativos, presença de monitores, museu com exposição de achados arqueológicos, loja de souvenir e espaço para eventos. A infraestrutura adequada nos sítios arqueológicos é um aspecto básico e fundamental para que estes sejam utilizados pela atividade turística.

Por fim, foi elaborado um roteiro turístico para agrupar os patrimônios arqueológicos identificados durante a pesquisa, de forma a atender turistas e moradores locais com interesses comuns.

\section{RESULTADOS E DISCUSSÃO}

\section{RECIFE ANTIGO: LEVANTAMENTO E DIAGNÓSTICO DOS SítIOS ARQUEOLÓGICOS DESTINADOS À ATIVIDADE TURÍSTICA}

Na pesquisa proposta pelo projeto $A$ atividade Turística na Cidade do Recife: Levantamento e Diagnóstico de Sítios Arqueológicos foi possível identificar, inicialmente, no Recife Antigo, cinco sítios que estão sendo utilizados na atividade turística: a Sinagoga KahalZur Israel, o Museu a Céu Aberto, o Forte do Brum, a Igreja da Madre de Deus, o Forte das Cinco Pontas e a Caixa Cultural (antiga Bolsa de Valores de Pernambuco e Paraíba).

Os sítios arqueológicos pesquisados estão inseridos no programa Fique Mais 1 Dia e em roteiros turísticos. Esses roteiros foram criados pela Secretaria de Turismo (SETUR) da Prefeitura do Recife, com o intuito de convencer o turista a passar mais um dia conhecendo a cidade através das programações. Dentre elas, Domingo no Recife, Recife Antigamente, Recife das Igrejas, Circuito Cultural Judaico, Recife dos Museus, Recife para Passageiros de Cruzeiros Marítimos, Recife Acessível e Recife para pessoa ldosa, estas são exatamente as programações do Fique Mais 1 Dia, no qual estão inseridos os patrimônios visitados durante a pesquisa de campo, os roteiros que 
podem ser seguidos a pé e que contemplam os patrimônios alvo da pesquisa são Marco Zero, Onde o Recife Começa e Dos Holandeses aos Mascates.

Apresenta-se, a seguir, o diagnóstico de cada um dos sítios arqueológicos identificados, analisando as suas características infraestruturais:

A Sinagoga Kahal Zur Israel - Está localizada na Rua do Bom Jesus e corresponde a primeira das Américas datada do século XVII. Durante a ocupação holandesa no Recife, muitos judeus das colônias portuguesas de Amsterdã e outros cristãos-novos começaram a praticar o judaísmo, visto que Mauricio de Nassau não proibia a prática de outros preceitos religiosos, porém às portas fechadas formando, assim, algumas congregações, inclusive a sinagoga, foram criadas. A liberdade religiosa permitiu a formação da comunidade judaica no período correspondente ao governo de Mauricio de Nassau (1637-1644), dessa forma houve uma imigração significante de judeus. Porém a partir de 1654, o governo português deu indícios de tentativas de reconquista das terras que estavam sob domínio holandês.

Durante as escavações arqueológicas realizadas como fase importante para realização do projeto arquitetônico com intuito de reconstituir traços originais da época do auge judaico no Recife, foram descobertos vestígios de cerâmica, cachimbos holandeses, entre outros artefatos, sendo que, principalmente, para a comunidade israelita, as maiores descobertas foram de acordo com Kaufman (2001) o "Bor", poço que alimenta o "Miqvê", utilizado para os banhos de purificação espiritual e de renovação dos judeus.

Atualmentea Sinagoga está aberta a visitação e é cobrada uma taxa de entrada no valor de cinco reais. Para os estudantes e idosos é cobrada meia-entrada. Esse dinheiro é destinado para a manutenção do sítio. Durante a visita de campo, pode-se observar a realização de uma reforma para implantação de um elevador de forma que o sítio possa ser acessível para pessoas que possuam limitações motoras.

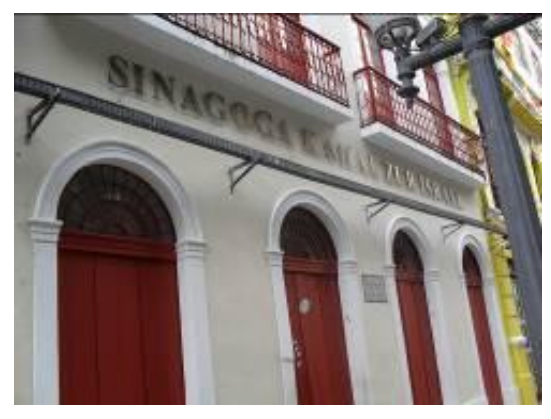

Fig. 02: Vista frontal da Sinagoga KahalZur Israel. Fonte: Vanessa Rodrigues, 2014.

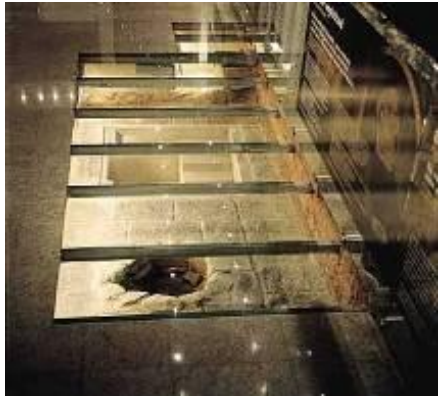

Fig. 03: exposição permanente protegida por vidro. 
$\mathrm{Na}$ Sinagoga Kahal Zurlsrael (Figura 02) pode-se verificar aspectos positivos e negativos em relação à preservação do patrimônio. Como pontos positivos, observou-se que a mesma possui uma infraestrutura que é composta por: sanitários adequados, loja de souvenir - com preço préestabelecido em real e em dólar - museu anexo, disponibiliza a área para eventos, as placas internas estão em português e inglês e em boas condições de visibilidade, os monitores têm conhecimento sobre a história do lugar e estão preparados para recepcionar e orientar os visitantes sobre questões de preservação e conservação. Existe no ambiente, também, uma réplica de templo, exposições do período holandês, achados arqueológicos e exposição de fotos, o piso possui proteção de vidro (Figura 03) e de grades de ferro onde é possível conservar o sítio e os turistas podem caminhar sem que haja destruição do mesmo.

Os pontos negativos são: as placas externas estão danificadas, sendo necessário que haja restauração das mesmas para que tantos os visitantes externos quanto os externos consigam ter uma boa visibilidade, não possui estacionamento próprio nem área de alimentação interna. Em relação à iluminação, algumas lâmpadas estavam sem funcionar. No momento da visita a esse sítio, não havia folders ou qualquer outro folheto explicativo. É indispensável que esse tipo de manutenção seja realizado. Sabemos que para a divulgação do conhecimento, é interessante e necessário que os visitantes recebam alguma meio de informação impresso.

Museu a Céu Aberto - Localizado entre as ruas Alfredo Lisboa e Barão Rodrigues Mendes, $\mathrm{s} / \mathrm{n}$, no bairro do Recife próximo da Torre Malakoff. A ideia de criar um museu a céu aberto teve o intuito de expor para a comunidade e para os turistas os achados arqueológicos encontrados que datam da época do governo holandês. Foi em meio às escavações para retirada de tubulações que foram achados parte da estrutura de muralha, além de fragmentos de outros materiais construtivos, cachimbos, azulejos portugueses e holandeses dos séculos XVI e XVII, faiança portuguesa e inglesa, porcelanas francesa e holandesa e algumas moedas.

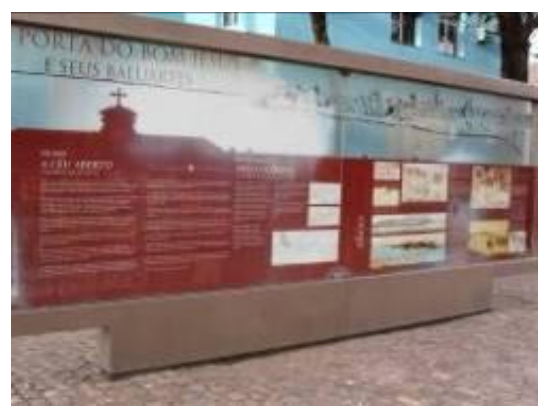

Fig. 04: Painel explicativo sobre o achado arqueológico. Fonte: Vanessa Rodrigues, 2014.

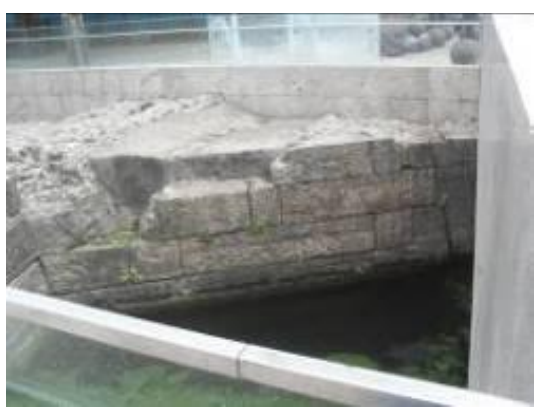

Fig. 05: Vista do Museu ao Céu Aberto. 
Apesar de fazer parte de alguns dos programas como o Fique Mais 1 Dia e dos roteiros Marco Zero e Onde o Recife Começa, estava, na época da visitação, em estado de abandono com parte da proteção de vidro trincada (Figura 05) e haviamuito lixo e acúmulo de esgoto no interior do sítio. O painel explicativo (Figura 04), onde se encontra informações da escavação, do material arqueológico e informação do próprio sítio, está bastante desgastado pela ação do sol e da chuva.

No sítio não havia presença de vigias para evitar que vândalos jogassem lixos e depredassem o mesmo. Na época da pesquisa de campo, verificou-se a necessidade também de manutenção e limpeza. Após a consolidação dos roteiros pré-estabelecidos pela Prefeitura do Recife, já pode-se notar mudanças significativas na área dos sítios. Observa-se os locais limpos e a presença de vigia, orientando os visitantes a não jogar lixo no interior dos sítios.

Forte do Brum - Unidade de defesa colonial, também conhecida por Fortaleza de São João Batista do Brum (Figura 06), durante sua construção em 1630, passou por situações adversas devido ao não conhecimento detalhado da região por parte dos responsáveis da construção, por exemplo, as chuvas intensas, logo no início dos trabalhos de construção, além da dificuldade de obter material como madeira, tijolos, telhas, pedra e cal, além dos ataques luso-brasileiros com vistas à reconquista do poderio holandês.

$\mathrm{Na}$ escavação arqueológica (Figura 07), foram revelados vestígios das primeiras construções, "contribuindo para o maior entendimento dos que construíram e lutaram nesta Fortificação" (ALBUQUERQUE; LUCENA; WALMSLEY, 1999: 72). Dentre os diversos tipos de vestígios encontram-se pregos, louças, cachimbos de fabricação holandesa e portuguesa, peças de jogos - que, provavelmente, devem ter entretido os guerreiros quando em momentos de paz temporária. - Esses dados permitem reconstituir informações sobre o dia-a-dia dos diferentes ocupantes de distintas épocas, enfim, reconstituir um pouco da história dessa fortificação.

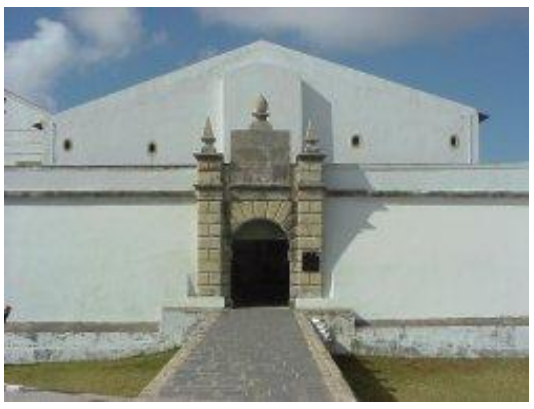

Fig. 06: Vista da entrada do Forte do Brum.

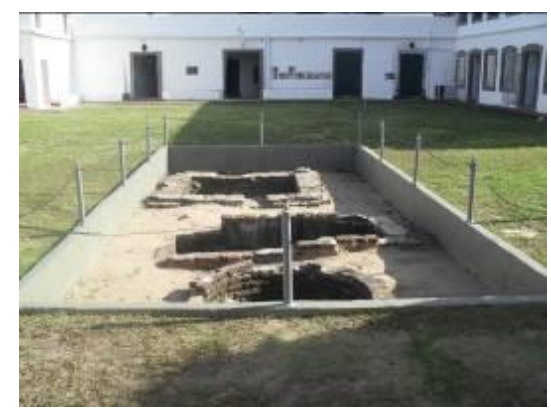

Fig. 07: Vista da escavação em evidência 
Atualmente, abriga o Museu Militar do Recife. Como pontos positivos, entre outros, apontase no museu a presença de um espaço para realização de eventos, estrutura arqueológica em evidência, material arqueológico exposto, material informativo impresso. Os pontos negativos seriam a presença de monitores (Soldados) não qualificados para atender os visitantes, ausência de sanitários, placas informativas não padronizadas.

Igreja da Madre de Deus - É um dos monumentos de grande importância para grupos católicos e os interessados em arte e história. Surgiu no final do século XVII e no século XVIII. A fundação e a reconstrução foram realizadas através de recursos financeiros da Congregação dos Oratorianos de S. Felipe Neri, ordem religiosa criada durante a Contra-Reforma na Itália e que se expandiu por França, Espanha e Portugal. Em Portugal, a ordem foi fundada por Bartolomeu de Quental e se consolidou firmemente graças aos favores alcançados por seu fundador junto à família real portuguesa (CARVALHO, 2008: 152)

Em 1685 e 1691, a igreja foi utilizada como local para sepultamentos das pessoas que morriam por causa da epidemia de febre amarela e na falta de cemitérios para sepultamento dos mortos era na igreja que se realizava os enterros. Mas os enterramentos na igreja foram proibidos, pois não havia mais espaço para colocar novos corpos e, muitas vezes, eram abertas covas com mortos ainda em estado de decomposição. E foi por determinação do governador de Pernambuco em 1691, o Marquês de Monte Belo, que "foram proibidos os sepultamentos dentro das igrejas, devendo os mortos serem inumados em locais determinados", entre os quais estavam o quintal da Igreja da Madre de Deus (CARVALHO et al., 2008 apud ANDRADE, 1969).

Durante a escavação para a drenagem de águas pluviais para a construção de um reservatório de água, solicitada pela Empresa de Urbanização do Recife, foram evidenciados fragmentos ósseos no pátio da igreja (Figura 09), sendo assim, o IPHAN - Instituto do Patrimônio Histórico, Artístico Nacional - foi comunicado, sendo encaminhada uma equipe de arqueologia para realizar o salvamento dos vestígios encontrados. Neste período, foi evidenciada uma estrutura construída em degraus de tijolo com argamassa de caliça, sem fundações, paralela à parede lateral da Igreja, uma construção circular de tijolo e pedra calcária unidos com argamassa de caliça., além de ossos humanos, fragmentos de faiança, louça, porcelana e fragmentos e metal. $\mathrm{Na}$ área do pátio da igreja, sob um antigo degrau construído para o acesso pela porta lateral da igreja, foram evidenciados restos humanos (CARVALHO et al., 2008: 05). 


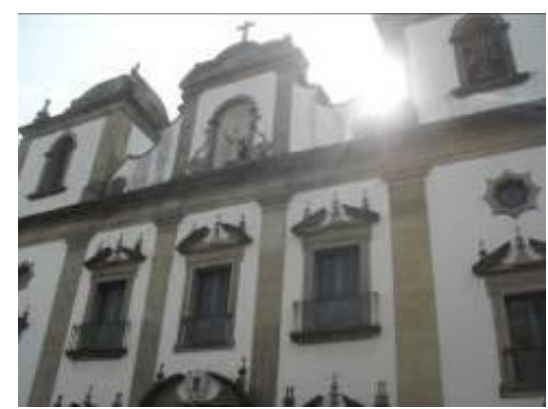

Fig. 08: Fachada Frontal da Igreja da Madre de Deus. Fonte: Vanessa Rodrigues, 2014.

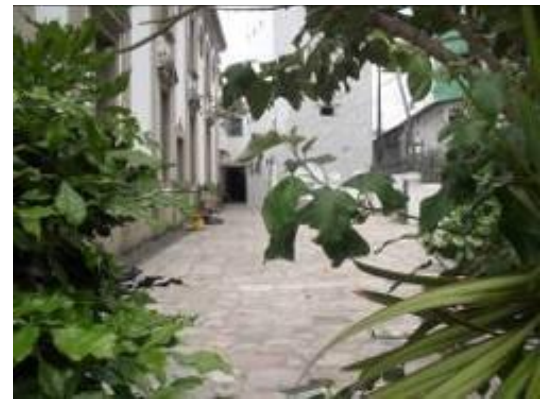

Fig. 09: Pátio da Igreja da Madre de Deus

A Igreja da Madre de Deus está inserida em programas e roteiros da Prefeitura do Recife e participou das três edições do Circuito das Igrejas que era de responsabilidade da Empresa Pernambucana de Turismo (EMPETUR) junto com a Fundação Gilberto Freyre. O pátio escavado serve de estacionamento e não está em evidência vestígios de que houve uma intervenção arqueológica no local. Existem monitores quando o Circuito das Igrejas os disponibilizam para recepcionar turistas e os mesmos fortalecem as questões da preservação e conservação da Igreja, porém não há informação sobre a intervenção arqueológica.

Interessante seria se houvesse, ao menos, placas ou banners, informando da escavação que existiu no pátio e de certa forma expor uma amostra do material encontrado, informando sobre a história, quais esqueletos foram identificados como masculino ou feminino, além de mostrar outros vestígios encontrados como a faiança, porcelana, metal. Sempre reforçar a importância da educação patrimonial, conservação dos vestígios e da própria igreja que foi marco importante na história de Recife.

Forte das Cinco Pontas- Em 1630, ano da invasão holandesa, foi dada a ordem de construção do Forte Frederick Henrich no sul da llha de Antônio Vaz - atualmente, localizado na llha de Santo Antônio ou Bairro de Santo Antônio - que ficou comumente conhecido como Forte das Cinco Pontas devido à sua forma pentagonal. A construção do forte preocupava os luso-brasileiros e estes, durante a construção, travaram uma batalha com os holandeses na tentativa de destruir o forte, pois construir um forte significaria demarcar uma área que passaria a ser de domínio holandês. Os luso-brasileiros não obtiveram êxito e os holandeses resolveram construir um reduto para proteção da construção do forte que foi denominado de reduto de Amélia ou Emilia. 
Quando Mauricio de Nassau chegou a Pernambuco, o forte se encontrava em estado de deterioração com muralhas desgastadas, fossos secos e aterrados, paliçadas em grande parte caídas pela deterioração das madeiras. Percebendo que o forte era muito importante e o único capaz de suprir com água às tropas, caso houvesse uma investida inimiga, mandou aprofundar os fossos, reforçar as muralhas entre outros melhoramentos (ALBUQUERQUE; LUCENA; WALMSLEY, 1999: 85).

Após a restauração, o forte continuou a servir como protetor de investidas inimigas. Em 1847 continuava em atividade e sua guarnição compunha-se de um capitão e 15 praças, e contava com 14 peças de bronze e 10 de ferro. Foi reconstruído em forma de quadrado composto por quatro baluartes e serviu como quartel e prisão. Outras reformas foram realizadas em 1637, 1684, 1822, 1904 e em 1979, esta última foi sob responsabilidade do convênio entre SEPLAN e SPHAN - atual IPHAN (ALBUQUERQUE; LUCENA; WALMSLEY, 1999: 86).

Atualmente, está aberto à visitação tanto dos moradores locais quanto dos turistas que acabam por conhecer um pouco da história de Pernambuco, pois em seu interior está inserido o Museu da Cidade do Recife onde é possível encontrar um acervo composto por peças, livros, mapas, peças de guerra, etc. Todo esse acervo serve de suporte para pesquisadores, estudantes e interessados. Constata-se, portanto, que o Forte das cinco pontas pode ser considerado um sítio arqueoturístico, pois nele existe a presença de monitores, museu anexo - Museu do Recife, sanitários e placas de informações em dois idiomas.

A Bolsa de Valores Pernambuco e Paraíba - O Edifício Arnaldo Dubeux foi construído em 1912 para abrigar o Bank of London \& South America Limited, sociedade bancária inglesa. Em 1976, foi adquirido pela Bolsa de Valores de Pernambuco e da Paraíba (BOVPP), mercado onde são efetuadas transações de compra e venda de produtos agrícolas e matérias primas ou valores mobiliários (GOMES, 1997). O prédio servia como espaço de diversas transações tanto para economia pernambucana quanto para a paraibana, onde ambos os estados poderiam comprar, vender produtos entre si e com outros estados. Nos últimos anos, estava fechado, sendo comprado pela Caixa Econômica Federal (CEF), que realizou um trabalho de restauração, onde foi necessária a intervenção arqueológica.

O monumento arquitetônico é um dos quatro que fica em frente à Praça Rio Branco conhecida como Marco Zero. O prédio foi tombado em 1998, pelo IPHAN. Na escavação arqueológica, foram encontrados fragmentos de cachimbos, porcelana, ossos e ruínas de antigos sobrados, muitos da época da ocupação holandesa (1630-1654). 


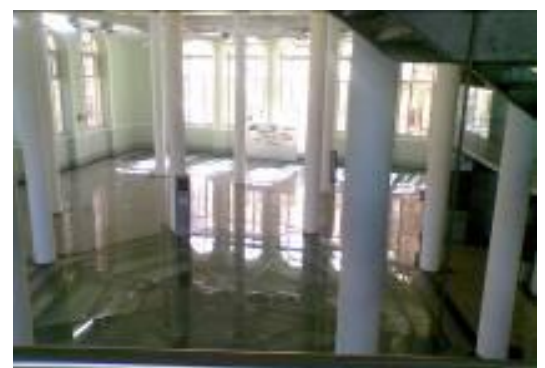

Fig. 12: Escavação evidenciada e protegida por vidro. Fonte: Vanessa Rodrigues, 2014

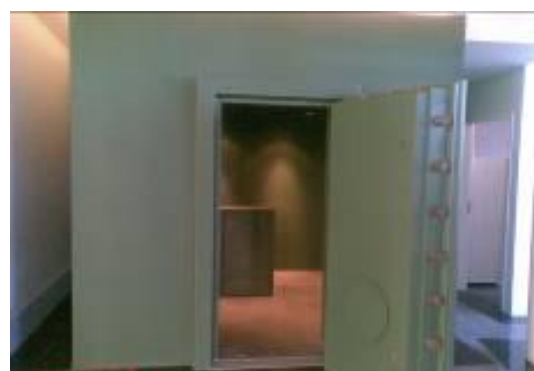

Fig. 13: Cofre da época do Banco de Londres. Fonte: Vanessa Rodrigues,

As estruturas originais identificadas durante as escavações foram protegidas por vidros (Figura 12). O cofre (Figura 13) da época das instalações do Banco de Londres está no ambiente. Ou seja, mais um monumento que deve ser incluso nos roteiros turísticos de Recife.

Atualmente, a Caixa Cultural foi aberta ao público, inaugurada no dia 15 de maio de 2012, e conta com museu, elevadores, monitores, recepção, exibição de filmes, shows culturais e exposições artísticas. A lanchonete e teatro estão em licitação para posterior funcionamento.

\section{MODELO DE ROTEIRO: NAS TRILHAS DA ARQUEOLOGIA}

A proposta do roteiro Nas Trilhas da Arqueologia baseou-se na existência do patrimônio que possui potencial significativo para seri nserido em um roteiro próprio. Procurou-se inserir os sítios arqueológicos com informações mais completas sobre a história e a cultura dos nossos antepassados. Esse roteiro contempla, portanto, várias culturas e grupos que contribuíram para a formação da população pernambucana: portugueses, negros, judeus e holandeses. Além de atrair turistas e moradores locais, essa proposta busca atrair também a atenção dos gestores públicos para investir na manutenção e na divulgação da preservação do patrimônio arqueológico. Assim foi definido o seguinte roteiro:

$>\quad$ Forte das Cinco Pontas

> Igreja da Madre de Deus

$>\quad$ Caixa Cultural (antiga Bolsa de Valores de Pernambuco e Paraíba)

$>$ Sinagoga KahalZur Israel

$>\quad$ Museu a Céu Aberto

$>\quad$ Forte do Brum

$>\quad$ Cruz do Patrão 
Os roteiros, geralmente, são criados como uma forma de preservar patrimônios de importância para sociedade. Dessa forma, é importante salientar a necessidade de uma contínua ação de educação patrimonial destinada para os turistas e moradores locais.

\section{CONSIDERAÇÕES FINAIS}

Durante o período de pesquisa, foi possível conhecer melhor questões sobre patrimônio, sítios arqueológicos, turismo e arqueologia. Verifica-se que esses campos estão se fortalecendo e se interdisciplinarizando, pois se complementam. Os sítios arqueológicos são redutos de conhecimentos, resguardam modos e fazeres dos nossos antepassados.

Cerâmica, louças e faianças, resíduos orgânicos, material lítico, vítreo e férreo, entre outros, são encontrados em grande parte nos sítios arqueológicos. Esses vestígios fornecem dados importantes do modo de vida, da dieta, da utilização dos vasilhames (decorativa ou utilitário), e podem fornecer dados sobre o status social e econômico de grupos do período histórico ou préhistórico.

Muitos patrimônios que passaram por intervenções arqueológicas estão sendo utilizados na prática da atividade turística, porém é necessário o uso consciente e sustentável do sítio de forma que permaneçam por mais tempo em bom estado de conservação e, posteriormente, as próximas gerações possam usufruir do conhecimento presente nesses sítios.

O levantamento permitiu identificar alguns sítios arqueológicos presentes no bairro do Recife Antigo que estão sendo utilizados como atrativos turísticos. O diagnóstico permitiu mostrar a situação atual desses sítios, revelando os pontos positivos e negativos da infraestrutura. Desta forma, forneceu os elementos necessários para definir uma gestão adequada para 0 desenvolvimento do turismo arqueológico, prevendo ações de proteção para que esse segmento turístico não seja utilizado de forma massiva e destrutiva. Na etapa seguinte, coma criação do Roteiro na Trilha da Arqueologia, será verificado como a comunidade poderá interagir de forma mais efetiva, havendo um intercâmbio maior entre os turistas e a população local, que possa servir não apenas para a troca de conhecimento, mas, sobretudo, com a finalidade de proteger melhor 0 patrimônio cultural.

\section{Referências bibliográficas}

ALBUQUERQUE, M; LUCENA, V; WALMSLEY, D. Fortes de Pernambuco: imagens do passado e do presente. Recife, 1999.

\begin{tabular}{|l|l|l|l|l|l|l|}
\hline (c) Rev. Arqueologia Pública & Campinas, SP & v.9 & n.2 & p.3-18 & DEZ-2015 & ISSN 2237-8294 \\
\hline
\end{tabular}


ALMEIDA, M. B. Noções básicas sobre metodologia de pesquisa científica. DTGI-ECI/UFMG, 2006. Disponível em: <http://mba.eci.ufmg.br/downloads/metodologia.pdf>.

ANDRADE, G. O. Montebelo, os males e os mascates, Recife: Editora da UFPE, 1969.

BENI, M. C. Análise estrutural do turismo. 6ª ed. São Paulo: SENAC, 2008.

CARVALHO, O. A, et al. Estudos Bioarqueológico na Igreja da Madre de Deus, Recife, Pernambuco: Exumação de Esqueletos humanos. In: MAX. Canindé, n.12, 2008.

FONSECA, J. J. S. Metodologia da pesquisa cientifica. UECE. Ceará, 2002. Disponível em: $<$ http://www.dqi.ufms.br/ |p4/apostilaMetodologia.pdf $>$.

GOMES, F. R. A bolsa de valores brasileira como fonte de informações financeiras. Perspect. cienc. inf., Belo Horizonte, v. 2, n. 2, p. 189 - 202, jul./dez.1997. Disponível em: <portaldeperiodicos.eci.ufmg.br/index.php/pci/article/download/>. Acesso em: 14 de Jul. de 2012.

GOELDNER, C. R. Turismo: princípios, práticas e filosofias. Porto Alegre: Bookman, 2002, p. 191,192 e 356.

GHETTI, N. C. Turismo arqueológico: Perspectivas para a preservação do patrimônio cultural e para a valorização social. Disponível: <http://www.ivtrj. net/sapis/2006/pdf/NeuvaniaGhetti.pdf >. Acesso em 26 out. 2009.

INSTITUTO DO PATRIMÔNIO HISTÓRICO ARTÍSTICO NACIONAL. Contrato e sociedade. Erechim, RS: Habilis, 2007. Pt. 2, cap.7, p. 81-91.

Carta de Laussane, 1990.

KAUFMAN, T. N. Sinagoga KahalZurlsrael: Guardiã de Memórias do Judaísmo. Entre o Sagrado e 0 Profano. Disponível em: $<$ http://www.arquivojudaicope.org.br/arquivos/bancodearquivos/81adca19ae427e5e427a744be334bc 25.pdf>. Acesso em: 21 de Ago. 2012.

MANZATO, F. Turismo arqueológico: Diagnóstico e análise do produto arqueoturístico. PASOS. São Paulo, v.5, n.1, p. 99-109, 2007. 
MINISTÉRIO DO TURISMO. Segmentação do turismo: marcos conceituais. Brasília, 2006.

PARDI, L. Preservação do patrimônio arqueológico e o turismo. Disponível em: <http://portal.jphan.gov.br/portal/baixaFCdAnexo.do?id=1097>. Acesso em: 20 set. 2009.

ORGANIZAÇÃO MUNDIAL DO TURISMO. Dados e fatos. Brasília, 2003. Disponível em: $<$ http://www.dadosefatos.turismo.gov.br/system/modules/br.gov.turismo.dadosfatos/templates/home/h ome resultado busca geral.jsp?tagsNone=OMT>.

RAMOS, A. C. T. Além dosmortos da Cruz do Patrão simbolismo e tradição no uso do espaço no Recife. Artigo apresentado na 26 ${ }^{\text {a }}$ Reunião Brasileira de Antropologia, realizada em junho, 2005, Porto Seguro, Bahia, Brasil.

REVISTA RECIFE TE QUER. Recife inusitado. Ed. Especial, 2010.

RODRIGUES, W. C. Metodologia cientifica. FAETEC/IST. Paracambi, 2007. Disponível em: $<$ http://professor.ucg.br/SiteDocente/admin/arquivosUpload/3922/material/Willian\%20Costa\%20Rodri gues metodologia cientifica.pdf>.

SEVERINO, A. J. Metodologia do trabalho científico. 23. ed. rev. e atual. São Paulo: Cortez, 2007.

SILVA, L. B. Turismo Histórico-Cultural em Recife-PE: um olhar sobre o Mercado de São José. Universidade Federal de Pernambuco, Recife/PE, 2008.

SOUZA, A. C; SOUZA, J.C. O patrimônio arqueológico da região metropolitana do Rio de Janeiro. Rio de Janeiro, 1981.

SCHLÜTER, R. Metodologia da pesquisa em turismo e hotelaria. Aleph. São Paulo, 2003. 